\title{
Plasma Free Amino Acid Profiles to Link Protein Malnutrition and Malnutrition Initiated Clinical Outcomes
}

Nagao $K^{1}$, Imaizumi $A^{1}$, Yamakado $\mathbf{M}^{2,3}$ and Kimura $\mathrm{T}^{4 *}$

${ }^{1}$ Institute for Innovation, Ajinomoto Co., Inc., Kawasaki 210-8681, Japan

${ }^{2}$ Department of Nursing, Ashikaga Institute for Technology, Tochigi 326-8558, Japan

${ }^{3}$ Center for Multiphasic Health Testing and Services, Mitsui Memorial Hospital, Tokyo 101-8643, Japan

${ }^{4}$ Ajinomoto Co., Inc., Tokyo 104-8315, Japan

\begin{abstract}
In this mini-review, we focus on essential and semi-essential amino acid concentrations in plasma as potential biomarkers for clinical consequences related to protein malnutrition. In Japan, protein malnutrition is common across varying populations, especially in elderly adults and young women, which could cause increased risk of sarcopenia, heart failure, impaired immune response, and conditions specific to women. After establishing clinical reference intervals for plasma free amino acid concentrations, we have reported the clinical characteristics of a Japanese subpopulation with low plasma free essential and semi-essential amino acid concentrations (Low-EAA), which we hypothesized to be potential protein malnutrition. Intriguingly, the ratio of the subjects with Low-EAA was varied depending on age and gender, with elderly subjects and young women having higher ratio of subjects with Low-EAA. After adjusting for age, sex, and BMI, Low-EAA was significantly associated with surrogate markers of protein malnutrition, anemia, cardiovascular diseases and infectious diseases. Plasma free amino acid concentrations could be not only a potential biomarker, but also a predictor for health problems associated with malnutrition.
\end{abstract}

Keywords: Essential and semi-essential amino acid; Protein malnutrition; Elderly; Young women; Biomarker

\section{Introduction}

The potential for using plasma amino acids as a metabolomic subset to identify disease risk has been shown $[1,2]$ and since 2011, a commercial service for cancer risk screening utilizing plasma amino acid concentrations has been commercially available in Japan [3].

Recently, accumulating evidence has revealed that the concentrations of Plasma Free Amino Acids (PFAAs); elevations of branched chain amino acids and aromatic amino acids, are associated with outcomes due to excessive nutritional intake such as visceral obesity [4], insulin resistance [5-7], and the future development of diabetes and cardiovascular diseases [8-10]. However, on the other hand, malnutrition or insufficient protein intake is also demonstrated to significantly affect PFAA profiles [11-13], although it has not been intensively researched so far. The present markers for malnutrition such as Body Mass Index (BMI), albumin or prealbumin are reported to fail in identifying subjects with protein-calorie malnutrition until extreme starvation [14-15]. In this mini-review, we focus on essential and semiessential amino acid concentrations in plasma which are lowered by protein malnutrition and illustrate a focused metabolomic approach to link malnutrition and nutrition-initiated clinical problems.

Animals require essential nutrients for growth and tissue function, which include vitamins, specific fatty acids, and certain amino acids. Although all plants can synthesize the 20 types of amino acids commonly found in proteins, animals are required to take in 9 essential amino acids: histidine, isoleucine, leucine, lysine, methionine, phenylalanine, threonine, tryptophan, and valine as food. Depending on the physiological and pathological conditions of the individual, in addition to these 9 amino acids, arginine may be required to maintain body protein homeostasis and is called a semi-essential amino acid. Insufficient protein intake could trigger low concentrations of essential and semi-essential amino acids in plasma [12,13]. Decrease in essential and semi-essential amino acid concentrations in plasma due to insufficient protein intake, could trigger protein malnutrition- initiated clinical problems, and thus, PFAAs are a potential marker for a person's health with regard to malnutrition and disease risks.

Protein malnutrition is common across varying populations, particularly elderly adults. It has been largely agreed that for the elderly population, the risk of malnutrition rather than over nutrition is the main cause for concern [16,17]. Protein malnutrition has been associated with increased risk of sarcopenia, heart failure, impaired immune response, impaired respiratory function, delayed wound healing, overall increased complications and increased mortality, especially in hospitalized or institutionalized subjects [18-20]. As for women, it is also reported that protein malnutrition could result in conditions specific to women, such as irregular menstruation, infertility, and low birth weight infants [21].

\section{Clinical Reference Intervals for Plasma Free Amino Acids (PFAAs)}

One of the issues in metabolomics is to consolidate the clinical reference intervals based on absolute concentrations in plasma in generally healthy subjects [2]. By comparing with the reference intervals, it could be diagnosed whether the concentrations of certain metabolites are low, normal, or high. We previously reported the clinical reference intervals for plasma free amino acid concentrations based on a validated high-performance liquid chromatography ionization mass spectrometry system [22-25]. In this study [25], reference individuals

*Corresponding author: Kimura T, Ph.D., Ajinomoto Co., Inc., Tokyo 104-8315, Japan Tel: +81 35250 8331; Fax: +81 35250 5054; E-mail: takeshi_kimura@ajinomoto.com

Received June 19, 2017; Accepted June 27, 2017; Published June 30, 2017

Citation: Nagao K, Imaizumi A, Yamakado M, Kimura T (2017) Plasma Free Amino Acid Profiles to Link Protein Malnutrition and Malnutrition Initiated Clinical Outcomes. Metabolomics (Los Angel) 7: 193. doi:10.4172/2153-0769.1000193

Copyright: (C) 2017 Nagao K, et al. This is an open-access article distributed under the terms of the Creative Commons Attribution License, which permits unrestricted use, distribution, and reproduction in any medium, provided the original author and source are credited. 
Citation: Nagao K, Imaizumi A, Yamakado M, Kimura T (2017) Plasma Free Amino Acid Profiles to Link Protein Malnutrition and Malnutrition Initiated Clinical Outcomes. Metabolomics (Los Angel) 7: 193. doi:10.4172/2153-0769.1000193

Page 2 of 5

were selected from 7,685 subjects who had undergone the Japanese health checkup system, Ningen Dock (Human Dry Dock) [26]. A total of 1,890 reference individuals who were generally-healthy based on exclusion criteria were selected after excluding outlier samples for each amino acid concentration. The lower limit of the reference intervals for the plasma amino acid concentrations was set at the $2.5^{\text {th }}$ percentile and the upper limit at the $97.5^{\text {th }}$ percentile (Table 1). The concentrations of most amino acids are more strongly related to sex than to age or BMI, and thus, the clinical reference intervals for PFAA concentrations were determined for each sex.

Recently, based on the reference intervals for PFAAs, we reported the clinical characteristics of a Japanese subpopulation with low plasma free essential and semi-essential amino acid concentrations (LowEAA), which we hypothesized to be potential protein malnutrition [27]. In the study, plasma free essential and semi-essential amino acids were quantified in a total of 10,102 Japanese subjects (age 20 to 88) that underwent the full health check-up system. Table 2 demonstrates the background clinical examination data of this study population.
This study population did not show a predisposition to any particular disease and did not have serious health problems. Low plasma amino acid concentrations were defined as lower than mean $-2 \times$ standard deviation after conversion to standardized values by referring the sex specific reference intervals for PFAAs [25]. Then, associations between Low-EAA (low concentrations of one or more of the following amino acids; Arg, His, Ile, Leu, Lys, Met, Phe, Thr, Trp, or Val) and deviations from health indicator reference ranges were analyzed. Among the 10,102 subjects, $16.6 \%$ were classified as the Low-EAA subpopulation.

Intriguingly, the ratio of the subjects with Low-EAA was varied depending on age and gender (Figure 1). The elderly subjects over 70 years of age had relatively higher ratio of subjects with Low-EAA in both males and females. Also, as for females, younger generations in their 30 s or 40 s had higher ratio of subjects with Low-EAA. It is well reported in Japan that both elderly [27] and young female [21,28,29] population have issues regarding malnutrition. Since malnutrition in the elderly could lead to sarcopenia; accelerated age-associated muscle loss, strength, and/or functionality, and malnutrition in young women

\begin{tabular}{|c|c|c|c|c|}
\hline \multirow{2}{*}{$(\mu \mathrm{mol} / \mathrm{L})$} & \multicolumn{2}{|c|}{ Male } & \multicolumn{2}{|c|}{ Female } \\
\hline & Lower limit & Upper limit & Lower limit & Upper limit \\
\hline Glutamate & 19.0 & 76.6 & 12.1 & 57.2 \\
\hline Serine & 82.8 & 149.0 & 80.3 & 157.0 \\
\hline Asparagine & 35.9 & 59.7 & 32.7 & 58.9 \\
\hline Glycine & 151.3 & 295.5 & 149.1 & 396.7 \\
\hline Glutamine & 467.3 & 702.0 & 413.8 & 668.6 \\
\hline Histidine & 66.8 & 101.1 & 62.6 & 92.7 \\
\hline Threonine & 88.3 & 169.6 & 68.1 & 168.5 \\
\hline Alanine & 239.1 & 491.8 & 203.0 & 442.9 \\
\hline Citrulline & 21.0 & 43.3 & 17.7 & 41.7 \\
\hline Arginine & 64.3 & 122.5 & 50.3 & 119.2 \\
\hline Proline & 94.0 & 243.3 & 70.4 & 187.9 \\
\hline a-Aminobutyric acid & 11.7 & 32.5 & 10.7 & 30.7 \\
\hline Tyrosine & 47.0 & 84.0 & 39.9 & 74.4 \\
\hline Valine & 182.1 & 295.3 & 137.5 & 242.5 \\
\hline Methionine & 20.2 & 34.2 & 17.0 & 29.6 \\
\hline Ornithine & 36.2 & 75.3 & 24.8 & 68.4 \\
\hline Lysine & 147.2 & 242.4 & 114.9 & 223.1 \\
\hline Isoleucine & 47.4 & 89.9 & 34.9 & 65.5 \\
\hline Leucine & 100.9 & 166.7 & 73.5 & 125.3 \\
\hline Phenylalanine & 46.6 & 74.9 & 41.9 & 66.3 \\
\hline Tryptophan & 47.4 & 76.9 & 40.9 & 68.0 \\
\hline
\end{tabular}

Table 1: Clinical reference intervals for plasma free amino acid concentrations of males and females [25].

\begin{tabular}{|c|c|c|c|}
\hline & Total & Male & Female \\
\hline Number of participants & 10102 & 6147 & 3955 \\
\hline \multicolumn{4}{|c|}{ Average \pm SD (Minimum-Maximum) } \\
\hline Age & $54.1 \pm 10.8(20-88)$ & $54.7 \pm 10.7(23-88)$ & $53.0 \pm 10.8(20-86)$ \\
\hline BMI, $\mathbf{k g} / \mathrm{m}^{2}$ & $22.7 \pm 3.2(13.9-43.3)$ & $23.7 \pm 2.9(14.9-43.3)$ & $21.2 \pm 3.1(13.9-41.3)$ \\
\hline Waist, cm & $82.7 \pm 9.3(54.0-160.0)$ & $86.2 \pm 7.9(62.0-160.0)$ & $77.3 \pm 8.8(54.0-121.0)$ \\
\hline SBP, $\mathrm{mmHg}$ & $121.3 \pm 18.2(65.0-214.0)$ & $125.2 \pm 17.4(65.0-214.0)$ & $115.2 \pm 17.8(76.0-198.0)$ \\
\hline DBP, $\mathrm{mmHg}$ & $76.6 \pm 11.2(34.0-138.0)$ & $79.5 \pm 10.5(34.0-138.0)$ & $72.2 \pm 10.8(42.0-116.0)$ \\
\hline Alb, g/dL & $4.4 \pm 0.2(2.5-5.4)$ & $4.5 \pm 0.2(2.5-5.4)$ & $4.4 \pm 0.2(3.0-5.1)$ \\
\hline LDLC, mg/dL & $123.2 \pm 30.0(17.0-294.0)$ & $123.8 \pm 29.3(17.0-276.0)$ & $122.2 \pm 31.0(24.0-294.0)$ \\
\hline TG, mg/dL & $112.8 \pm 101.6(15.0-5661.0)$ & $131.7 \pm 121.0(21.0-5661.0)$ & $83.5 \pm 46.7(15.0-572.0)$ \\
\hline HbA1c, \% & $5.3 \pm 0.6(3.3-12.5)$ & $5.4 \pm 0.6(3.4-12.5)$ & $5.2 \pm 0.4(3.3-12.1)$ \\
\hline FBG, mg/dL & $97.9 \pm 17.5(60.0-356.0)$ & $101.4 \pm 19.2(62.0-356.0)$ & $92.4 \pm 12.7(60.0-293.0)$ \\
\hline
\end{tabular}

BMI: Body Mass Index; SBP: Systolic Blood Pressure; DBP: Diastolic Blood Pressure; Alb: Albumin; LDLC: Low-density Lipoprotein Cholesterol; TG: Triglyceride; FBG: Fasting Blood Glucose 
Citation: Nagao K, Imaizumi A, Yamakado M, Kimura T (2017) Plasma Free Amino Acid Profiles to Link Protein Malnutrition and Malnutrition Initiated Clinical Outcomes. Metabolomics (Los Angel) 7: 193. doi:10.4172/2153-0769.1000193

Page 3 of 5

could lead to irregular menstruation and possibly lead to infertility, it is seen as being problematic.

\section{Lower Amino Acid Concentrations as Potential Link between Malnutrition and Future Outcomes}

In this study Imaizumi et al. [30], we also tested the association between the subjects with Low-EAA and the surrogate markers related to protein malnutrition, anemia, cardiovascular diseases and infectious diseases (Table 3). After adjusting with age, sex, and BMI, the LowEAA was significantly associated with the 4 protein malnutritionassociated markers (lower albumin, total protein, total cholesterol, and LDL-cholesterol), 3 anemia-associated markers (lower hemoglobin, hematocrit, and mean corpuscular hemoglobin), 3 sympathetic nerve activity-associated markers (higher heartbeats, neutrophils, and lower inorganic phosphorus), and 2 inflammation and immune functionassociated markers (higher neutrophils and C-reactive protein). Although there is no clear evidence regarding causal relationship so far, these changes, such as higher heartbeats or C-reactive protein might be associated with increased risk of future heart failure or impaired immune response. It is reported that tryptophan concentration in blood is inversely associated with cardiovascular disease, and an increase in the plasma tryptophan concentration by the Mediterranean diet was significantly associated with a decreased risk of cardiovascular disease [31]

Currently, the importance of leucine and essential amino acids in plasma is well reported and that leucine stimulates protein synthesis primarily by activating the Mammalian Target of Rapamycin (mTOR) signaling pathway. The stimulation of muscle protein synthesis is primarily due to essential amino acids since there is net protein synthesis only when essential amino acids are ingested [32]. The muscle protein synthesis is stimulated to a similar extent when non-essential amino acids are removed from a total amino acid mixture [32]. Thus, increased risk of sarcopenia due to protein malnutrition could be partly due to a Low-EAA condition. Ingestion of a leucine-enriched essential amino acid nutrient solution rapidly activates mTOR signaling pathway and protein synthesis in human skeletal muscle [33]. Further, mTOR signaling and muscle protein synthesis are enhanced when leucineenriched nutrients are ingested following exercise [34-36].

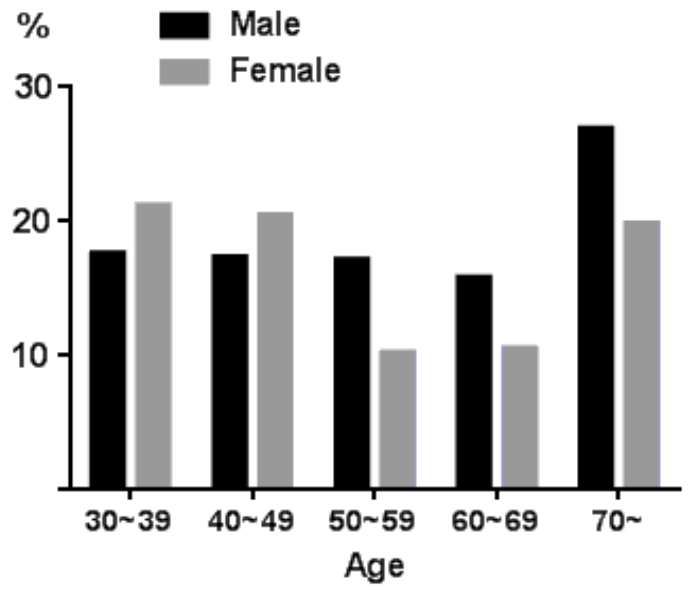

Figure 1: The ratio of the subjects with Low-EAA. Low-EAA: Low blood concentrations in essential and semi-essential amino acids (Arg, His, lle, Leu, Lys, Met, Phe, Thr, Trp, and Val) compared with clinical reference interval for each amino acid [30].

\begin{tabular}{|c|c|c|c|c|c|}
\hline & & $\begin{array}{l}\text { No adjustment } \\
\text { (All subjects) }\end{array}$ & $\begin{array}{l}\text { No adjustment } \\
\text { (Male) }\end{array}$ & $\begin{array}{c}\text { No adjustment } \\
\text { (Female) }\end{array}$ & $\begin{array}{l}\text { Adjustment }^{*} \\
\text { (All subjects) }\end{array}$ \\
\hline Beats & Upper limit & $3.10(2.06$ to 4.60$)$ & 2.31 (1.35 to 3.86$)$ & 5.04 (2.56 to 9.83$)$ & 3.21 (2.18 to 4.72$)$ \\
\hline LDH & Upper limit & 2.06 (1.51 to 2.77 ) & 2.19 (1.49 to 3.17$)$ & 1.81 (1.03 to 3.05$)$ & 2.33 (1.73 to 3.15$)$ \\
\hline Amy & Upper limit & 1.55 (1.22 to 1.95$)$ & $1.72(1.28$ to 2.30$)$ & $1.29(0.84$ to 1.93$)$ & 1.27 (1.00 to 1.61$)$ \\
\hline HDL-C & Upper limit & 1.41 (1.24 to 1.59$)$ & 1.74 (1.46 to 2.06 ) & 1.26 (1.04 to 1.52$)$ & 1.24 (1.09 to 1.42$)$ \\
\hline $\mathrm{Cl}$ & Upper limit & 2.06 (1.70 to 2.49$)$ & 2.13 (1.68 to 2.70$)$ & 1.88 (1.33 to 2.63 ) & 2.16 (1.78 to 2.61$)$ \\
\hline MCV & Upper limit & 2.19 (1.58 to 2.99$)$ & 2.08 (1.46 to 2.91$)$ & 2.18 (0.83 to 5.16$)$ & 0.55 (0.29 to 1.02$)$ \\
\hline $\mathrm{MCH}$ & Upper limit & 1.83 (1.39 to 2.38 ) & 1.73 (1.29 to 2.29$)$ & 1.83 (0.71 to 4.22$)$ & 1.70 (1.24 to 2.32 ) \\
\hline PLT & Upper limit & 1.69 (1.26 to 2.24$)$ & 1.74 (1.14 to 2.61$)$ & 1.74 (1.14 to 2.60$)$ & $0.87(0.57$ to 1.33$)$ \\
\hline Neut & Upper limit & $3.09(2.54$ to 3.75$)$ & 3.22 (2.48 to 4.16$)$ & $3.04(2.24$ to 4.11$)$ & 1.84 (1.39 to 2.44$)$ \\
\hline CRP & Upper limit & 1.95 (1.60 to 2.36$)$ & 1.87 (1.49 to 2.34$)$ & 1.99 (1.33 to 2.94$)$ & 2.17 (1.79 to 2.64$)$ \\
\hline T-Bil & Lower limit & 2.15 (1.65 to 2.78 ) & $2.92(2.05$ to 4.11$)$ & $1.52(0.98$ to 2.30$)$ & 2.26 (1.75 to 2.92$)$ \\
\hline TP & Lower limit & $1.71(1.35$ to 2.16$)$ & 1.93 (1.42 to 2.60$)$ & $1.47(0.99$ to 2.15$)$ & 1.68 (1.33 to 2.11$)$ \\
\hline Alb & Lower limit & 2.15 (1.74 to 2.64$)$ & 2.66 (1.98 to 3.56$)$ & 1.88 (1.38 to 2.54$)$ & 2.32 (1.89 to 2.85 ) \\
\hline TC & Lower limit & 1.77 (1.37 to 2.26$)$ & 1.83 (1.34 to 2.47$)$ & $1.58(0.98$ to 2.49$)$ & 1.62 (1.27 to 2.08$)$ \\
\hline LDL-C & Lower limit & 2.21 (1.71 to 2.83 ) & 2.37 (1.71 to 3.26 ) & 2.01 (1.32 to 3.02 ) & 1.92 (1.50 to 2.46$)$ \\
\hline HbA1c & Lower limit & 1.77 (1.32 to 2.37$)$ & 1.60 (1.05 to 2.39$)$ & 2.08 (1.33 to 3.18$)$ & 1.57 (1.17 to 2.09 ) \\
\hline IP & Lower limit & 2.71 (1.70 to 4.25$)$ & 2.90 (1.77 to 4.69$)$ & 1.04 (0.11 to 4.76$)$ & 2.64 (1.71 to 4.09$)$ \\
\hline $\mathrm{Ca}$ & Lower limit & 1.55 (1.34 to 1.79$)$ & 1.56 (1.29 to 1.89$)$ & 1.60 (1.28 to 2.01$)$ & 1.56 (1.35 to 1.80$)$ \\
\hline RBC & Lower limit & 2.36 (1.99 to 2.79 ) & 2.45 (2.03 to 2.96 ) & 1.64 (1.05 to 2.51$)$ & 1.00 (0.00 to Inf) \\
\hline $\mathrm{Hb}$ & Lower limit & 2.80 (2.37 to 3.31$)$ & 2.95 (2.41 to 3.61$)$ & 2.41 (1.77 to 3.26 ) & 1.97 (1.65 to 2.35$)$ \\
\hline $\mathrm{Ht}$ & Lower limit & 3.23 (2.62 to 3.98$)$ & 3.69 (2.85 to 4.75$)$ & 2.40 (1.62 to 3.51$)$ & 2.49 (2.11 to 2.94$)$ \\
\hline $\mathrm{MCH}$ & Lower limit & 1.59 (1.26 to 1.99$)$ & 2.41 (1.48 to 3.85$)$ & 1.63 (1.24 to 2.13$)$ & 1.59 (1.24 to 2.05$)$ \\
\hline Lympho & Lower limit & 1.80 (1.59 to 2.04$)$ & 1.73 (1.47 to 2.02$)$ & 1.92 (1.56 to 2.36$)$ & 1.14 (0.60 to 2.17$)$ \\
\hline $\mathrm{Fe}$ & Lower limit & 2.65 (1.92 to 3.62$)$ & N.T. & 2.65 (1.92 to 3.62$)$ & 1.01 (0.50 to 2.02 ) \\
\hline
\end{tabular}

Low-EAA: Low blood concentrations in essential and semi-essential amino acids (Arg, His, lle, Leu, Lys, Met, Phe, Thr, Trp, and Val)

N.T.; Not tested. Parenthesis represent odds ratios with $95 \%$ confidence interval. *Adjusted with age, sex, and BMI. The cells contain significant values ( $p<0.05$ ) are colored. Source; Imaizumi et al. [30]

Table 3: The odds ratios of subjects who are outside the reference intervals of each clinical health indicator in the Low-EAA population. 
Other studies have shown that plasma amino acids have the potential to be developed as predictive markers for diseases such as diabetes and metabolic syndrome [8,9]. If Low-EAA conditions can be used as early markers of protein malnutrition, it may be possible to perform early nutritional interventions for at risk individuals to reduce the risk of progression to subsequent disease states. Under Low-EAA conditions, depending on the kinds of amino acids which are low, physiological impact may differ. Future research to link malnutrition, changes in metabolites, and physiological outcomes are needed.

\section{Conclusion}

The potential for using plasma amino acid concentrations as markers for certain physiological and disease states have been well documented, and there is now evidence that Low-EAA levels may be an early marker for protein malnutrition. Protein malnutrition is common across varying populations, including elderly adults and young females, which could cause increased risk of sarcopenia, heart failure, impaired immune response, and conditions specific to women. Further metabolomics research to link malnutrition, decrease in essential and semi-essential amino acids, and physiological outcomes would be valuable to devise methods of early nutritional interventions to prevent or ameliorate deleterious outcomes.

\section{Conflict of Interests}

$\mathrm{KN}, \mathrm{AI}$ is employees and TK is a Board Member of Ajinomoto Co., Inc. MY received research grants from Ajinomoto Co., Inc. This does not alter the authors' adherences to all of the journal policies. No other potential conflicts of interest in relation to this article are declared.

\section{References}

1. Noguchi Y, Zhang QW, Sugimoto T, Furuhata Y, Sakai R, et al. (2006) Network analysis of plasma and tissue amino acids and the generation of an amino index for potential diagnostic use. Am J Clin Nutr 83: 513S-519S.

2. Imaizumi A, Nishikata N, Yoshida H, Yoneda J, Takehana S, et al. (2012) Clinical Implementation of Metabolomics. In: Roessner DU (ed.). Metabolomics: InTech pp: 289-314.

3. Spotlight on Kawasaki (2012) Nature jobs.

4. Yamakado M, Tanaka T, Nagao K, Ishizaka Y, Mitushima T, et al. (2012) Plasma amino acid profile is associated with visceral fat accumulation in obese Japanese subjects. Clin Obes 2: 29-40.

5. Tai ES, Tan ML, Stevens RD, Low YL, Muehlbauer MJ, et al. (2010) Insulin resistance is associated with a metabolic profile of altered protein metabolism in Chinese and Asian-Indian men. Diabetologia 53: 757-767.

6. Wurtz P, Makinen VP, Soininen P, Kangas AJ, Tukiainen T, et al. (2012) Metabolic signatures of insulin resistance in 7,098 young adults. Diabetes 61 : 1372-1380.

7. Nakamura H, Jinzu H, Nagao K, Noguchi Y, Shimba N, et al. (2014) Plasma amino acid profiles are associated with insulin, C-peptide and adiponectin levels in type 2 diabetic patients. Nutr Diabetes 4: e133.

8. Wang TJ, Larson MG, Vasan RS, Cheng S, Rhee EP, et al. (2011) Metabolite profiles and the risk of developing diabetes. Nat Med 17: 448-453.

9. Yamakado M, Nagao K, Imaizumi A, Tani M, Toda A et al. (2015) Plasma free amino acid profiles predict four-year risk of developing diabetes, metabolic syndrome, dyslipidemia, and hypertension in Japanese population. Sci Rep 5.

10. Nagao K, Yamakado M (2016) The role of amino acid profiles in diabetes risk assessment. Curr Opin Clin Nutr Metab Care 19: 328-335.

11. Polge A, Bancel E, Bellet H, Strubel D, Poirey S, et al. (1997) Plasma amino acid concentrations in elderly patients with protein energy malnutrition. Age Ageing 26: 457-462.

12. Fujita $Y$, Yoshimura $Y$, Inoue $G$ (1978) Effect of low-protein diets on free amino acids in plasma of young men: effect of protein quality with maintenance or excess energy intake. J Nutr Sci Vitaminol (Tokyo) 24: 297-309

13. Fujita Y, Yamamoto T, Rikimaru T, Inoue G (1979) Effect of low protein diets on free amino acids in plasma of young men: effect of wheat gluten diet. J Nutr Sci Vitaminol (Tokyo) 25: 427-439.

14. Lee JL, Oh ES, Lee RW, Finucane TE (2015) Serum Albumin and Prealbumin in Calorically Restricted, Nondiseased Individuals: A Systematic Review. Am J Med 128: 1023e1-1023e22.

15. Komai S, Watanabe Y, Fujiwara Y, Kim H, Edahiro A, et al. (2016) Association between the nutritional status and the severity of sarcopenia among communitydwelling elderly Japanese people. Nihon Ronen Igakkai Zasshi 53: 387-395.

16. Tamakoshi A, Yatsuya H, Lin Y, Tamakoshi K, Kondo T, et al. (2010) BMI and all-cause mortality among Japanese older adults: findings from the Japan collaborative cohort study. Obesity (Silver Spring) 18: 362-369.

17. Kobayashi S, Asakura K, Suga H, Sasaki S (2013) Three-generation study of women on D, health study $\mathrm{G}$. high protein intake is associated with low prevalence of frailty among old Japanese women: a multicenter cross-sectional study. Nutr J 12.

18. Milne AC, Potter J, Vivanti A, Avenell A (2009) Protein and energy supplementation in elderly people at risk from malnutrition. Cochrane Database Syst Rev.

19. Sargento L, Longo S, Lousada N, dos Reis RP (2014) The importance of assessing nutritional status in elderly patients with heart failure. Curr Heart Fail Rep 11: 220-226.

20. Dennison EM, Sayer AA, Cooper C (2017) Epidemiology of sarcopenia and insight into possible therapeutic targets. Nat Rev Rheumatol 13: 340-347.

21. Kodama $H$ (2010) Problems of underweight in young females and pregnant women in Japan. JMAJ 53: 285-289.

22. Shimbo K, Yahashi A, Hirayama K, Nakazawa M, Miyano H (2009) Multifunctional and highly sensitive precolumn reagents for amino acids in liquid chromatography/tandem mass spectrometry. Anal Chem 81: 5172-5179.

23. Shimbo K, Kubo S, Harada Y, Oonuki T, Yokokura T, et al. (2010) Automated precolumn derivatization system for analyzing physiological amino acids by liquid chromatography/mass spectrometry. Biomed Chromatogr 24: 683-691.

24. Yoshida H, Kondo K, Yamamoto H, Kageyama N, Ozawa S, et al. (2015) Validation of an analytical method for human plasma free amino acids by high-performance liquid chromatography ionization mass spectrometry using automated precolumn derivatization. J Chromatogr B Analyt Technol Biomed Life Sci 998-999: 88-96.

25. Yamamoto $\mathrm{H}$, Kondo $\mathrm{K}$, Tanaka $\mathrm{T}$, Muramatsu $\mathrm{T}$, Yoshida $\mathrm{H}$, et al. (2016) Reference intervals for plasma-free amino acid in a Japanese population. Ann Clin Biochem 53: 357-364.

26. Ikeda N, Saito E, Kondo N, Inoue M, Ikeda S, et al. (2011) What has made the population of Japan healthy? Lancet 378: 1094-1105.

27. Yuki A, Ando F, Otsuka R, Matsui Y, Harada A, et al. (2015) Epidemiology of sarcopenia in elderly Japanese. J Phys Fit Sport Med 4: 111-115.

28. Nishida T, Sakakibara H (2010) Association between underweight and low lymphocyte count as an indicator of malnutrition in Japanese women. $J$ Womens Health (Larchmt) 19: 1377-1383.

29. Takimoto H, Yoshiike N, Kaneda F, Yoshita K (2004) Thinness among young Japanese women. Am J Public Health 94: 1592-1595.

30. Imaizumi A, Nagao K, Jinzu H, Tanaka T, Kageyama Y, et al. (2017) Clinica characteristics of a subpopulation of low plasma free essential and semiessential amino acid levels in Japanese. Ningen Dock 31: 709-717.

31. Yu E, Ruiz-Canela M, Guasch-Ferre M, Zheng Y, Toledo E, et al. (2017) Increases in plasma tryptophan are inversely associated with inciden cardiovascular disease in the Prevencion con Dieta Mediterranea (PREDIMED) study. J Nutr 147: 314-322.

32. Volpi E, Kobayashi H, Sheffield-Moore M, Mittendorfer B, Wolfe RR (2003) Essential amino acids are primarily responsible for the amino acid stimulation of muscle protein anabolism in healthy elderly adults. Am J Clin Nutr 78: 250 258

33. Drummond MJ, Rasmussen BB (2008) Leucine-enriched nutrients and the regulation of mammalian target of rapamycin signalling and human skeletal muscle protein synthesis. Curr Opin Clin Nutr Metab Care 11: 222-226. 
Citation: Nagao K, Imaizumi A, Yamakado M, Kimura T (2017) Plasma Free Amino Acid Profiles to Link Protein Malnutrition and Malnutrition Initiated Clinical Outcomes. Metabolomics (Los Angel) 7: 193. doi:10.4172/2153-0769.1000193

Page 5 of 5

34. Dreyer HC, Drummond MJ, Pennings B, Fujita S, Glynn EL, et al. (2008) Leucine-enriched essential amino acid and carbohydrate ingestion following resistance exercise enhances mTOR signaling and protein synthesis in human muscle. Am J Physiol Endocrinol Metab 294: E392-E400.

35. Kim HK, Suzuki T, Saito K, Yoshida H, Kobayashi H, et al. (2012) Effects of exercise and amino acid supplementation on body composition and physical function in community-dwelling elderly Japanese sarcopenic women: randomized controlled trial. J Am Geriatr Soc 60: 16-23.

36. Kim H, Suzuki T, Saito K, Kojima N, Hosoi E, et al. (2016) Long-term effects of exercise and amino acid supplementation on muscle mass, physical function and falls in community-dwelling elderly Japanese sarcopenic women: A 4-year follow-up study. Geriatr Gerontol Int 16: 175-181. 